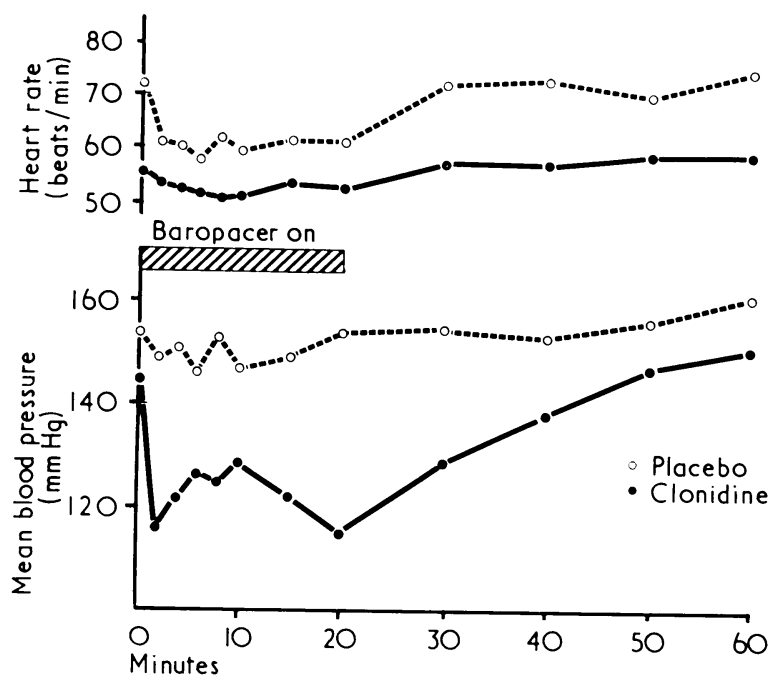

Effect of baropacer stimulation on blood pressure and heart rate during low-( $\odot$ ) and high-(O)dose clonidine treatment. Each point on the graph represents mean value of 4-hourly readings following administration of clonidine or placebo.

Stimulation of afferent carotid sinus nerves in our patient during low-dose clonidine treatment resulted in a relatively small fall in blood pressure compared with the depressor response observed on the highdose day. Since the experimental conditions were otherwise similar, it appears that clonidine facilitated medullary vasomotor neurones, the central component of the baroreceptor reflex, producing a decrease in sympathetic outflow and hence blood pressure.

In considering the hypotensive action of clonidine, the drug may also directly inhibit central sympathetic activity by a mechanism which may be independent of its effects on baroreceptor function." The relative importance of baroreceptor facilitation and direct central sympathetic inhibition to the observed hypotensive response in treated patients remains unknown.

I am the recipient of an Ontario Heart Foundation Senior Research Fellowship.

${ }^{1}$ Schwartz, S I, et al, American fournal of Surgery, 1967, 114, 5.

2 Korner, P I, et al, European fournal of Pharmacology, 1974, 28, 189.

${ }^{3}$ Haeusler, G, Naunyn-Schmiedeberg's Archives of Pharmacology, 1974, 285, 1.

+ Sleight, P, and West, M J, in Blood Pressure Regulation, ed D S Davies and J L Reid, p 291. University Park Press, London, 1975.

${ }^{5}$ VanZweiten, P A, fournal of Pharmacy and Pharmacology, 1973, 25, 89.

Division of Cardiology, Sunnybrook Hospital, Toronto, Ontario M4N 3M5, Canada

MARTIN G MYERS, MD, FRCP(C), consultant physician

\section{Intravenous glucose tolerance and maintenance haemodialysis}

Carbohydrate intolerance is common in uraemia and is generally ${ }^{1}$ believed to improve with regular haemodialysis. This opinion, however, is based on studies in which the glucose concentration was measured by non-specific reducing methods, which yield falsely raised values for uraemic sera. ${ }^{2}$ Thus dialysis may seem to improve glucose tolerance by removing reducing substances other than glucose, such as creatinine, uric acid, etc. ${ }^{2}$ In one recent study, ${ }^{3}$ in which plasma glucose was measured by a glucose-specific enzymatic method, the response of patients with end-stage renal failure, either undialysed or on regular haemodialysis, to an oral glucose load was not improved after dialysis.

We used a glucose-specific assay method to study the acute effect of dialysis on the response to intravenous glucose in 10 uraemic patients on maintenance haemodialysis.

\section{Patients and methods}

We studied eight male and two female uraemic patients, aged $42 \pm 4$ (mean \pm standard error of mean) years and within $94 \pm 5 \%$ of their desirable weight. They had no family histories of diabetes mellitus and no known glucose intolerance before the onset of renal failure. They also showed no evidence of gastrointestinal or endocrine disorders, had had no recent intercurrent illness or weight change, and hyperparathyroidism was not detected clinically or by $x$-ray examination. All patients were on a free diet, with at least $200-\mathrm{g}$ carbohydrate intake daily; salt was unrestricted. They were on a thriceweekly, five-hour haemodialysis schedule for $27 \pm 9$ months. The dialysis bath contained no glucose.

Each patient was studied the first time shortly (range $0 \cdot 2-17$ hours) after dialysis ("post-dialysis") and the second time 65-109 hours after deliberate withdrawal of dialysis ("predialysis"), the order of the two studies being randomised. On both occasions fasting blood was drawn for creatinine, methylguanidine, nitrogen, potassium, and glucose measurements; $0.33 \mathrm{~g} / \mathrm{kg}$ glucose as a 40 ". minute period; and plasma samples for glucose measurement were taken $2 \cdot 5,5,7 \cdot 5,10,15,20,25,30,35,40,50$, and 60 minutes afterwards. All patients agreed to having their dialysis postponed and to participating in the investigation.

Creatinine, nitrogen, and potassium were measured by standard techniques, and methylguanidine by chromatography; glucose was assayed by the glucose oxidase method (Glucose Analyser, Beckman Instrument). Glucose $\mathrm{k}$ value (fractional removal rate) was computed by monoexponential interpolation of the absolute glucose readings from 10 to 60 minutes after injection, with the use of least squares analysis. We used the paired $t$ test to compare the means of the post- and predialysis values.

\section{Results and comment}

Post-dialysis serum creatinine concentrations fell from $1379 \pm 97$ to $628 \pm 44: \mathrm{mol} / 1(15 \cdot 6 \pm 1 \cdot 1$ to $7 \cdot 1 \pm 0.5 \mathrm{mg} / 100 \mathrm{ml}(\mathrm{P}<0.001)$; plasma methylguanidine from $11 \cdot 2 \pm 1 \cdot 2$ to $7 \cdot 9 \pm 1 \cdot 0 \mu \mathrm{mol} / 1(98 \pm 11$ to $69 \pm 9$ ug $100 \mathrm{ml}) \quad(\mathrm{P}<0.05)$; nitrogen from $136.4 \pm 6$ to $60.7 \pm 5 \mathrm{mmol} / \mathrm{l}$ $(191 \pm 8$ to $85 \pm 7 \mathrm{mg} / 100 \mathrm{ml})(\mathrm{P}<0.001)$; and serum potassium from $6.4 \pm 0.4$ to $4.4 \pm 0.2 \mathrm{mmol}(\mathrm{mEq}) / 1(P<0.01)$. Average plasma glucose concentrations, however, were higher at all the sampling points in the post-dialysis period (figure). One patient was intolerant to intravenous glucose $(k$ value $<1)$ before dialysis, and three were so after dialysis. Glucose $k$ value increased in one patient, remained about the same in five, and decreased in four. The difference between the means $(1.69 \pm 0.1 \%$ min before and $1.35 \pm 0.1 \% / \mathrm{min}$ after dialysis $)$ was not statistically significant.

On average our patients' ability to dispose of an acute glucose load was no better in the shorter period after dialysis-despite the effective

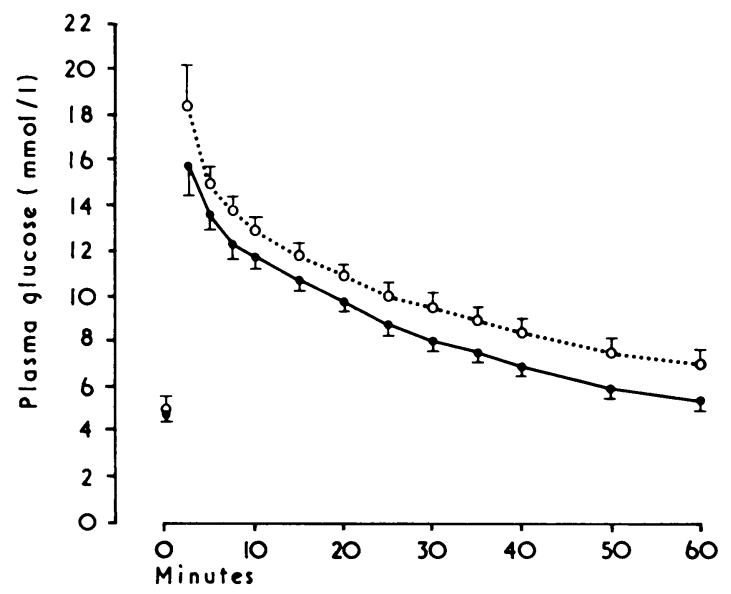

Mean ( \pm standard error of mean) plasma glucose concentrations after $0.33 \mathrm{~g} / \mathrm{kg}$ intravenous glucose in 10 ureamic patients on maintenance haemodialysis $77 \pm 5$ hours (closed spaces) and $6 \pm 2$ hours (open spaces) after last dialysis.

Conversion: SI to traditional units-Blood glucose $/ \mathrm{mmol} / 1$ $\approx 18 \mathrm{mg} / 100 \mathrm{ml}$. 
removal of reducing substances and uraemic toxins. It would therefore seem justified to conclude that haemodialysis does not improve the glucose tolerance of patients on maintenance haemodialysis, as measured by the intravenous test. Nevertheless, $k$ values are rather uncertain criteria, since plasma glucose disappearance curves are not usually monoexponential. Furthermore, the dynamics of insulinglucose interactions are imperfectly described by a single parameter. ${ }^{4}$ On the other hand, the metabolic performance of patients on chronic haemodialysis is basally depressed, and is intermittently challenged by such stresses as dehydration, blood-pressure and flow changes, and electrolyte depletion. This might explain why we obtained the lowest $\mathrm{k}$ values from the tests performed at the shortest time (about 15 minutes) after the dialytic stress. Different test conditions or treatment of data may well give different results. ${ }^{5}$ Hence the acute effects of haemodialysis on glucose tolerance are probably weak, transitory, and altogether unpredictable.

This study was partly supported by a grant (NO1-AM-8-0707) from the US Public Health Service.

1 Brenner, B M, and Rector, F C, The Kidney. Philadelphia, Saunders, 1976.

2 Powell, J B, and Djuh, Y, American fournal of Clinical Pathology, 1971, $56,8$.

3 Swenson, R S, Weisinger, J, and Reaven, G M, Metabolism, 1974, 23, 929.

${ }^{4}$ Insel, P A, et al, fournal of Clinical Investigation, 1975, 55, 1057.

${ }^{5}$ Davidson, M B, Lowrie, E G, and Hampers, C L, Metabolism, 1969, 18, 387.

(Accepted 6 May 1977)

CNR Clinical Physiology Laboratory, Second Medical Clinic and Institute of Medical Pathology, University of Pisa, Italy

E FERRANNINI, MD, investigator

A PILO, MSC, investigator

G BUZZIGOLI, chief technician

C BONI, technician

M TUONI, MD, clinical assistant

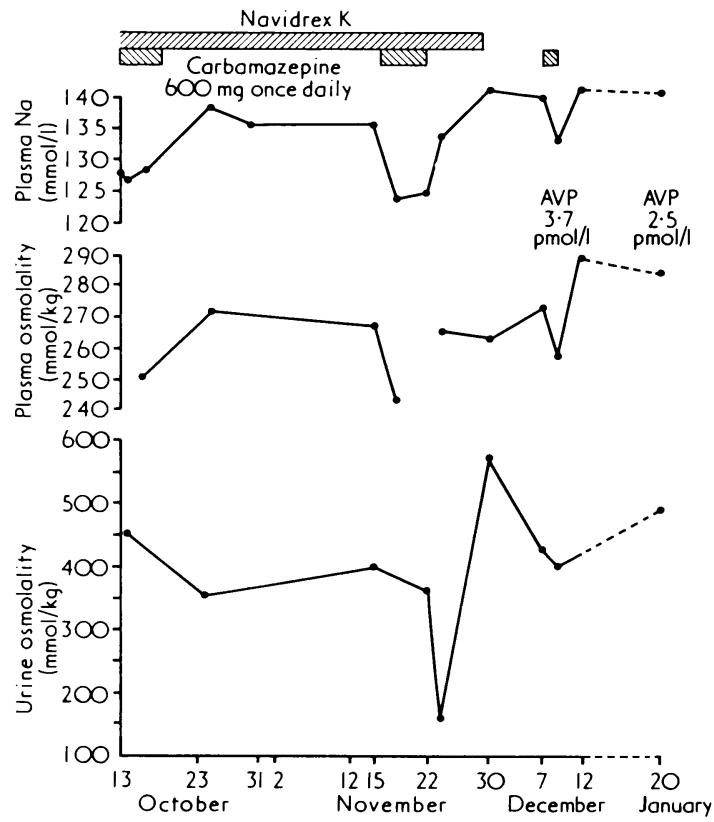

Urine osmolality and plasma sodium, osmolality, and AVP concentrations with and without treatment with carbamazepine and Navidrex $\mathrm{K}$.

Conversion: SI to traditional units-Urine and plasma osmolality: $1 \mathrm{mmol} / \mathrm{kg}=1 \mathrm{mOsm} / \mathrm{kg}$. Plasma sodium:

$1 \mathrm{mmol} / 1=1 \mathrm{mEq} / \mathrm{l}$. Plasma AVP: $1 \mathrm{pmol} / 1 \approx 1.08 \mathrm{pg} / \mathrm{ml}$.

osmolality (284 mmol $/ \mathrm{kg})$. Plasma cortisol at $2.15 \mathrm{pm}$ was $338 \mathrm{nmol} / 1$ $(12 \cdot 2 \mu \mathrm{g} / 100 \mathrm{ml})$.

\section{Discussion}

Carbamazepine is one of many drugs that have been associated with inappropriate antidiuresis. ${ }^{4}$ Its mode of action is not clearly understood, though it may stimulate vasopressin secretion, impair vasopressin degradation, potentiate vasopressin's renal action, or have an independent, direct effect on the renal tubule. Although there is much indirect evidence that the antidiuretic action of carbamazepine is mediated through an increased plasma vasopressin concentration, ${ }^{4}$ some workers have reported low concentrations of immunoreactive plasma AVP in patients taking this drug. ${ }^{5}$

Our patient's hyponatraemia appeared to be related only to carbamazepine treatment. Interaction with a diuretic was excluded, and hyponatraemia recurred on reintroduction of carbamazepine. Furthermore, the hyponatraemia, low plasma osmolality, and high urine osmolality with normal renal and adrenal function could be attributed to the syndrome of inappropriate antidiuretic hormone secretion, and inappropriately high concentrations of plasma AVP were found. This supports the indirect evidence referred to above. ${ }^{4}$

A major problem has been measurement of extremely low plasma concentrations of AVP by either bioassay or immunoassay. With the recent improvement of radioimmunoassay techniques for measuring plasma AVP we expect confirmation that carbamazepine exerts its antidiuretic effect by raising the concentration of endogenous vasopressin.

${ }^{1}$ Stephens, W P, et al, British Medical fournal, 1977, 1, 754.

${ }^{2}$ Henry, D A, et al, British Medical fournal, 1977, 1, 83.

${ }^{3}$ Baylis, P H, and Heath, D A, Clinical Endocrinology, 1977, 7, 91.

* Miller, M, and Moses, A M, Kidney International, 1976, 10, 96.

5 Meinders, A E, Cejka, V, and Robertson, G L, Clinical Science and Molecular Medicine, 1974, 47, 289.

(Accepted 17 fune 1977)

Derbyshire Royal Infirmary, Derby DE1 2QY

N J SMITH, MB, MRCP, registrar in neurology

M L E ESPIR, MB, FRCP, consultant neurologist

University Department of Medicine, Queen Elizabeth Hospital, Birmingham B15 2TH

P H BAYLIS, MB, MRCP, senior registrar carbamazepine she was no longer hyponatraemic and the plasma AVP concentration $(2.5 \mathrm{pmol} / 1 ; 2.7 \mathrm{pg} / \mathrm{ml})$ was appropriate for the plasma 